\title{
Analisis Prediksi Jumlah Pasien Rawat Inap di Rumah Sakit GMIM Siloam Sonder Menggunakan Metode Triple Exponential Smoothing
}

\author{
Feibe Lawalata ${ }^{1}$, Eko Sediyono ${ }^{2}$, Hindriyanto Purnomo ${ }^{3}$ \\ 1 Prodi Magister Sistem Informasi UKSW;2 Prodi Magister Sistem Informasi UKSW; 3 Prodi Magister Sistem Informasi UKSW \\ Email: lawalatafeibe@gmail.com
}

\begin{abstract}
The increase in patients that occurs every month needs to be considered by every hospital, be it private hospitals or government hospitals. With the predictive value of the number of patients for each month. It is hoped that it can help hospital management, in making decisions to improve patient service facilities, especially in inpatient installations. In this study, the forecasting method used is Triple Exponential Smoothing, because this method is quite simple and also has advantages. The triple exponential smoothing method can adjust the trend of changes and seasonal components. The research was conducted at GMIM Siloam Sonder General Hospital, by taking samples in the form of data on the number of patients for the last 3 years using excel format. From the results of the analysis carried out, the forecast results obtained for the next 3 years are an increase seen from the increase in the total number of patients each year. The forecast value obtained is classified into high-accuracy forecasting because it has a MAPE value $\leq$ of $10 \%$.
\end{abstract}

Keywords — forecasting, triple exponential smoothing, hospital

Abstrak - Lonjakan pasien yang terjadi setiap bulannya perlu diperhatikan oleh setiap rumah sakit, baik itu rumah sakit swasta maupun rumah sakit pemerintah. Dengan adanya nilai prediksi jumlah pasien untuk setiap bulannya. Diharapkan dapat membantu manajemen rumah sakit, dalam pengambilan keputusan untuk meningkatkan fasilitas pelayanan pasien khususnya dalam instalasi rawat inap. Dalam penelitian ini metode peramalan yang digunakan yaitu Triple Exponential Smoothing, karena metode tersebut cukup sederhana dan juga memiliki kelebihan. Metode triple exponential smoothing mampu menyesuaikan trend perubahan dan komponen musiman. Penelitian dilakukan di RSU GMIM Siloam Sonder, dengan mengambil sampel berupa data jumlah pasien 3 tahun terakhir dengan format excel. Dari hasil analisis yang dilakukan, hasil peramalan yang didapatkan untuk 3 tahun kedepan yaitu terjadi peningkatan dilihat dari meningkatnya jumlah total pasien setiap tahun. Nilai peramalan yang didapatkan tergolong ke dalam peramalan akurasi tinggi karena memiliki nilai MAPE $\leq \mathbf{1 0 \%}$.

Kata Kunci-forecasting, triple exponential smoothing, rumah sakit

\section{PENDAhUluan}

Rumah sakit merupakan unit yang bergerak di bidang kesehatan, pelayanan dan fasilitas rumah sakit yang baik adalah hal yang harus diperhatikan karena akan memberikan dampak positif kepada pasien yang menerima pelayanan sehingga rumah sakit tersebut akan menjadi pilihan utama pasien dalam melakukan pengobatan.

Rumah sakit merupakan institusi pelayanan kesehatan yang menyelenggarakan pelayanan kesehatan perorangan secara paripurna (promotif, preventif, kuratif dan rehabilitatif) yang menyediakan pelayanan rawat inap, rawat jalan dan gawat darurat yang berperan penting untuk meningkatkan derajat kesehatan masyarakat [1]. Unit rawat inap memiliki peran penting dalam pengelolaan rumah sakit karena penghasilan terbesar berasal dari pelayanan yang diberikan oleh unit tersebut.

Salah satu hal yang perlu diperhatikan rumah sakit yaitu pelayanan untuk pasien rawat inap, maka dari itu rumah sakit memerlukan data prediksi jumlah pasien rawat inap untuk beberapa tahun ke depan dengan data tersebut, rumah sakit dapat memantau kebutuhan pasien kedepannya.
Dalam peramalan, hal yang perlu diperhatikan yaitu nilai error yang didapatkan. Untuk mendapatkan hasil peramalan yang baik, diperlukan metode peramalan yang baik pula, semakin kecil nilai error yang didapat maka semakin baik hasil peramalan yang dihasilkan. Hasil peramalan yang baik tersebut dapat digunakan rumah sakit dalam pengembangan pelayanan rumah sakit[2].

Rumah sakit GMIM Siloam Sonder merupakan rumah sakit yang dikelola oleh Yayasan Medika GMIM, terletak di kabupaten Minahasa. Rumah sakit ini merupakan rumah sakit tertua di Indonesia Timur yang berdiri sejak tahun 1901.

Ketersediaan pelayanan untuk pasien adalah hal yang penting, khususnya di bagian pelayanan rawat inap[3]. Oleh sebab itu, perlu dilakukan prediksi jumlah pasien rawat inap, sehingga rumah sakit mempunyai bayangan kebutuhan pasien kedepannya. Metode peramalan yang digunakan yaitu Triple Exponential Smoothing, metode tersebut cukup sederhana serta memiliki kelebihan mampu menyesuaikan tren perubahan dan komponen musiman[4][5][6]. Penelitian ini bertujuan mengetahui prediksi jumlah pasien untuk 3 tahun kedepan di Rumah Sakit GMIM Siloam Sonder dari tahun 2020-2022. 


\section{TINJAUAN PUSTAKA}

\section{A. Penelitian Sebelumnya}

Penelitian yang dilakukan oleh Anggraini, tentang Time Series Forecasting Using Exponential Smoothing To Predict The Number of Website Visitor of Sebelas Maret University. Hasil dari penelitian yang dilakukan menggunakan exponential smoothing, metode triple exponential smoothing dikategorikan sebagai peramalan baik dengan kesalahan perhitungan (MAPE) nilai $10,27 \%[7]$.

Penelitian yang dilakukan oleh Ryan, tentang Modeling of Time Series Data Prediction using Fruit Fly Optimization Algorithm and Triple Exponential Smoothing. Hasil dari penelitian yang dilakukan, kombinasi dari FOA-TES bisa memprediksi data dengan nilai rata-rata MAPE 6\% lebih baik dari prediksi TES dengan peningkatan nilai MAPE $4 \%[8]$

Penelitian yang dilakukan oleh Rini, tentang Forecasting The Number of Patients at RSUD Sukoharjo Using Double Exponential Smoothing Holt. Hasil dari penelitian yang dilakukan menunjukan, penelitian dengan menggunakan double exponential smoothing dinilai dari 3 metode MAE,MSE, dan MAPE menunjukkan nilai error lebih kecil dari $10 \%$ sehingga prediksi menggunakan DES Holt termasuk dalam kategori sangat baik[7].

Hasil dari penelitian-penelitian sebelumnya, metode yang baik dan cocok untuk peramalan dalam penelitian ini yaitu metode Exponential Smoothing yang ditambahkan metode Holt-Winters additive dengan trend multiplicative damped.

\section{B. Prediksi atau Peramalan}

Prediksi atau peramalan dapat dikatakan sebagai kegiatan dalam hal memperkirakan apa yang akan terjadi di masa yang akan datang. Hal ini dilakukan dengan memperhatikan data atau informasi masa lalu atau saat ini baik secara matematik atau statistic. Prediksi bertujuan untuk mengetahui, melihat dan memperkirakan kegiatan usaha.

Sebuah prediksi dapat bersifat kualitatif (tidak berbentuk angka) ataupun kuantitatif (berbentuk angka). Dalam perancangan suatu metode prediksi atau peramalan, terdapat 3 tahapan yaitu[9] :

- Melakukan analisis pada data masa lampau. Langkah ini bertujuan untuk mendapatkan gambaran pola dari data bersangkutan

- Memilih metode yang akan digunakan, terdapat banyak sekali metode peramalan yang tersedia. Pemilihan metode dapat mempengaruhi hasil ramalan. Hasil ramalan diukur dengan menghitung error atau kesalahan terkecil, oleh sebab itu tidak ada metode peramalan yang pasti baik untuk semua jenis data.

- Proses transformasi dari data masa lampau dengan menggunakan metode yang dipilih. Apabila diperlukan maka diadakan perubahan sesuai dengan kebutuhannya.

Berdasarkan data yang didapatkan dari rumah sakit, pemilihan model yang tepat dengan data yang ada yaitu menggunakan Metode Triple Exponential Smoothing. Hasil dari plot data yang didapatkan, data rumah sakit memiliki trend sekaligus variasi musiman.

\section{Triple Exponential Smoothing}

Triple Exponential Smoothing (TES), biasa disebut dengan Holt-Winter Model adalah model peramalan yang mengasumsikan bahwa metode perhitungan data observasi memiliki trend sekaligus variasi musiman. Perhitungan TES hampir sama dengan DES tetapi ada penambahan nilai konstan gamma dalam menghaluskan komponen musiman, dengan rumus perhitungan [4]:

$$
\begin{gathered}
F_{t}=\alpha \frac{D_{t}}{I_{t-L}}+(1-\alpha)\left(F_{t-1}-T_{t-1}\right) \\
T_{t}=\beta\left(F_{t}-F_{t-i}\right)+(1-\beta) T_{t-i} \\
I_{t}=\delta \frac{D_{t}}{F_{t}}+(1-\delta) I_{t-L} \\
F_{t+1}=\left(F_{t}+T_{t}\right) I_{t-L}
\end{gathered}
$$

Dimana :

$I_{t}=$ index seasonal dalam period $-\mathrm{t}$

$\delta=$ konstan penghalusan komponen musiman

$L=$ panjang musim

Nilai alpha, beta dan gamma dalam kisaran 0 sampai 1 . Semakin besar nilai konstanta, maka semakin besar pembobotan terhadap pemberian observasi data.

\section{Perhitungan Kesalahan}

Keakuratan model matematika dalam format peramalan ditentukan dengan menghitung kesalahan (error) yang sedang terjadi, kesalahan perhitungan melibatkan rata-rata dari beberapa fungsi selisih antara nilai aktual dan perkiraan.

Selisih antara nilai peramalan yang sebenarnya biasanya disebut sebagai residual. Persamaan untuk menghitung nilai residual atau error asli setiap periode peramalan adalah sebagai berikut [9]:

$$
E=D_{t}-F_{t}
$$

Adapun fungsi kesalahan perhitungan dalam suatu metode perhitungan peramalan adalah :

- Membantu menemukan model yang optimal

- Sebagai alat untuk mengukur apakah teknik yang diambil dapat dipercaya atau tidak

- Membandingkan akurasi dua atau lebih metode berbeda

Kesalahan dapat ditampilkan dalam nilai dan persentase asli, Persentase Error (PE) digunakan untuk mengukur keakuratan nilai dugaan model yang dinyatakan dalam bentuk persentase. Berikut rumus menghitung PE :

$$
P E=\frac{\left|D_{t}-F_{t}\right|}{D_{t}}
$$

Sedangkan kesalahan persentase mean absolute (MAPE) digunakan untuk mengukur keakuratan nilai dugaan suatu model yang dinyatakan dalam bentuk persentase absolut 
rata-rata dari keseluruhan error. Berikut rumus untuk menghitung MAPE :

$$
M A P E=\frac{1}{n} \sum_{t=1}^{n} \frac{\left|D_{t}-F_{t}\right|}{D_{t}}
$$

Dimana :

$\mathrm{D}_{\mathrm{t}}=$ Nilai data actual periode $\mathrm{t}$

$\mathrm{F}_{\mathrm{t}}=$ Nilai data periode ramalan $\mathrm{ke}-\mathrm{t}$

$\mathrm{n}$ = banyak data

\section{Metode Penelitian}

Untuk jenis penelitian yang digunakan yaitu penelitian deskriptif dengan analisis data kuantitatif bertujuan untuk memprediksi jumlah pasien di instalasi rawat inap Rumah Sakit RSU GMIM Siloam Sonder.

Penelitian ini dilakukan di RSU GMIM Siloam Sonder, analisis yang dilakukan adalah pada instalasi rawat inap RSU GMIM Siloam sonder. Informasi diambil dari Rumah Sakit, Data diambil dalam format excel. Adapun variabel yang digunakan yaitu, jumlah pasien dari tahun 2017 sampai tahun 2019.

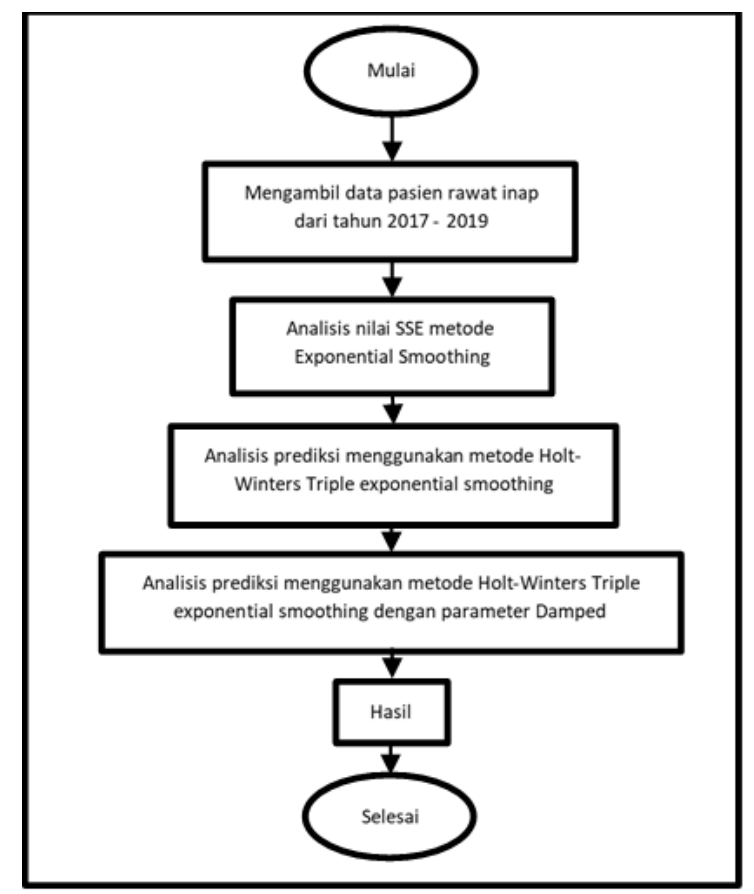

Gbr. 1 Alur Penelitian

\section{HASIL DAN PEMBAHASAN}

Data pada penelitian ini diambil dari Rumah Sakit GMIM Siloam Sonder dalam format Excel yang berisi data jumlah pasien rawat inap dari tahun 2017 sampai tahun 2019, gambaran data dapat dilihat pada Tabel I.

\section{TABEL I. DATA JUMLAH PASIEN RAWAT INAP TAHUN 2017 SAMPAI TAHUN 2019}

\begin{tabular}{|c|c|c|c|}
\hline \multirow{2}{*}{ Bulan } & \multicolumn{3}{|c|}{ Tahun } \\
\cline { 2 - 4 } & $\mathbf{2 0 1 7}$ & $\mathbf{2 0 1 8}$ & $\mathbf{2 0 1 9}$ \\
\hline Januari & 255 & 256 & 251 \\
\hline Februari & 237 & 252 & 253 \\
\hline Maret & 178 & 190 & 185 \\
\hline
\end{tabular}

\begin{tabular}{|c|c|c|c|}
\hline April & 211 & 210 & 209 \\
\hline Mei & 252 & 229 & 235 \\
\hline Juni & 224 & 220 & 208 \\
\hline Juli & 184 & 190 & 191 \\
\hline Agustus & 188 & 180 & 190 \\
\hline September & 174 & 195 & 206 \\
\hline Oktober & 223 & 230 & 229 \\
\hline November & 221 & 211 & 213 \\
\hline Desember & 213 & 193 & 248 \\
\hline
\end{tabular}

Data yang ada pada Tabel 1, merupakan jumlah total pasien rawat inap dari setiap ruangan di rumah sakit RSU GMIM Siloam Sonder.

Berdasarkan hasil analisis yang dilakukan dari model Single Exponential Smoothing, Double Exponential Smoothing, dan Triple Exponential Smoothing didapatkan hasil nilai Sum Square Error (SSE). Nilai SSE dapat dilihat pada Tabel II.

TABEL III. HASIL SUM SQUARE ERROR 3 MODEL EXPONENTIAL SMOOTHING

\begin{tabular}{|l|c|}
\hline \multicolumn{2}{|c|}{ Model Exponential Smoothing } \\
\hline \multicolumn{1}{|c|}{ Model } & $\begin{array}{c}\text { Sum Square Error } \\
\text { (SSE) }\end{array}$ \\
\hline $\begin{array}{l}\text { Single Exponential } \\
\text { Smoothing }\end{array}$ & 28166,62 \\
\hline $\begin{array}{l}\text { Double Exponential } \\
\text { Smoothing }\end{array}$ & 35279,79 \\
\hline $\begin{array}{l}\text { Triple Exponential } \\
\text { Smoothing }\end{array}$ & 3690,655 \\
\hline $\begin{array}{l}\text { Single Exponential } \\
\text { Smoothing }\end{array}$ & 28166,62 \\
\hline
\end{tabular}

Berdasarkan tabel diatas, nilai SSE (Sum Square Error) terkecil menunjukkan bahwa model tersebut cocok untuk digunakan dalam peramalan. Nilai SSE yang mendekati 0 menandakan bahwa model tersebut mempunyai komponen kesalahan acak terkecil dan nilai tersebut akan lebih berguna untuk peramalan terhadap suatu model yang diamati.

Berdasarkan analisis R didapatkan nilai SSE untuk model Single Exponential Smoothing sebesar 28166,62, nilai SSE untuk model Double Exponential Smoothing sebesar 35279,79, dan nilai SSE untuk model Triple Exponential Smoothing sebesar 3690,665. Sehingga yang menjadi model terbaik yaitu Triple Exponential Smoothing, karena menghasilkan nilai SSE terkecil yaitu 3690,655.

Dengan hasil yang didapatkan, model Triple Exponential Smoothing bagus digunakan untuk peramalan jumlah pasien rawat inap di RSU GMIM Siloam Sonder. dalam metode tersebut terdapat dua metode Holt-Winters yaitu additive dan multiplicative, setelah ditemukan metode terbaik kemudian diuji kembali menggunakan parameter damped.

Pemilihan metode Holt-Winters yang baik, dapat dilihat dari nilai MAPE yang ada. Parameter nilai MAPE dapat di lihat di Tabel III.

\section{TABEL IIIII. PARAMETER NILAI MAPE}

\begin{tabular}{|l|c|}
\hline \multicolumn{2}{|c|}{ Model Exponential Smoothing } \\
\hline Model & Sum Square Error (SSE) \\
\hline MAPE $\leq 10 \%$ & Peramalan Akurasi Tinggi \\
\hline $10 \%<\mathrm{MAPE} \leq 20 \%$ & Peramalan Bagus \\
\hline
\end{tabular}




\begin{tabular}{|l|c|}
\hline $20 \%<\mathrm{MAPE} \leq 50 \%$ & Perkiraan Wajar \\
\hline MAPE $>50 \%$ & Peramalan Tidak Akurat \\
\hline
\end{tabular}

Hasil dari peramalan menggunakan metode additive selama 3 tahun kedepan dapat dilihat pada gambar 8.

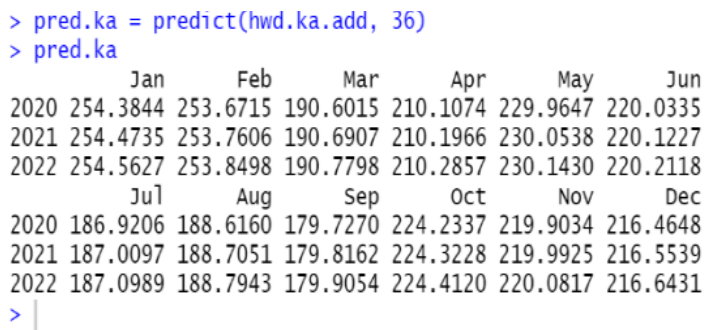

Gbr. 3 Hasil dari Prediksi Menggunakan Metode Holt-Winter Additive

Dari hasil peramalan menggunakan metode additive, didapatkan hasil pada tahun 2020 bulan januari sebesar 254 , februari sebesar 253, maret sebesar 190, april sebesar 210, mei sebesar 229, juni sebesar 220, juli sebesar 186, agustus sebesar 188, september sebesar 179 , oktober sebesar 224, november sebesar 219, desember sebesar 216.

Pada tahun 2021 bulan januari sebesar 254, februari sebesar 253, maret sebesar 190, april sebesar 210, mei sebesar 230, juni sebesar 220, juli sebesar 187, agustus sebesar 188, september sebesar 179, oktober sebesar 224, november sebesar 219, desember sebesar 216 .

Pada tahun 2022 bulan januari sebesar 254, februari sebesar 253, maret sebesar 190, april sebesar 210, mei sebesar 230, juni sebesar 220, juli sebesar 187, agustus 188, september sebesar 179, oktober sebesar 224, november sebesar 220, dan desember sebesar 216.

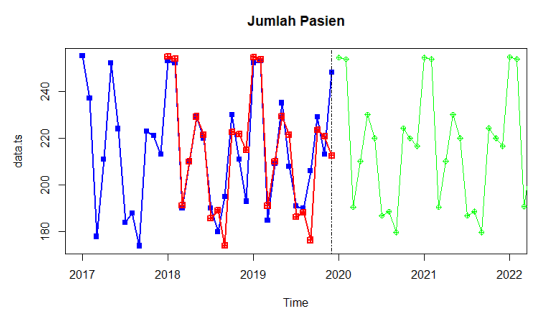

Gbr. 4 Hasil Plot Data Holt Winter Additive

Dapat dilihat bahwa garis biru merupakan data aktual, garis merah merupakan fitted value atau dugaan dari data yang kita miliki dan hijau merupakan hasil dari peramalan yang dilakukan dengan metode additive. Terlihat juga garis merah mengikuti pola garis biru yang artinya nilai dugaan yang kita miliki mengikuti pola dari data.

Selanjutnya menambahkan parameter damped pada trend dengan menggunakan package forecast pada RStudio, dengan menggunakan metode additive dan metode multiplicative. Model peramalan yang dilakukan untuk menentukan nilai dari parameter $\alpha, \beta$, dan $\gamma$ tepat untuk menghasilkan nilai MAPE terkecil[10] hasilnya dapat dilihat pada gambar 10 dan 11.

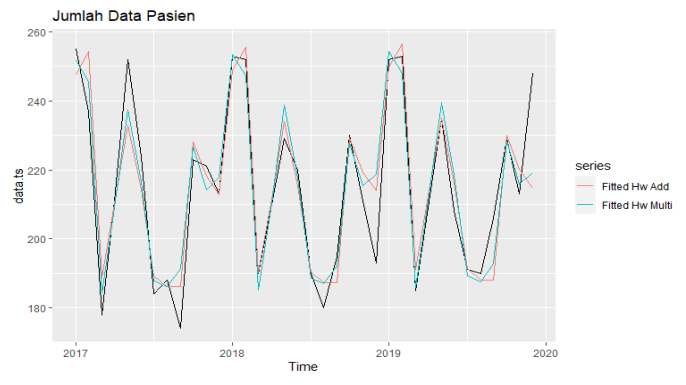

Gbr. 5 Hasil Autoplot Fitted

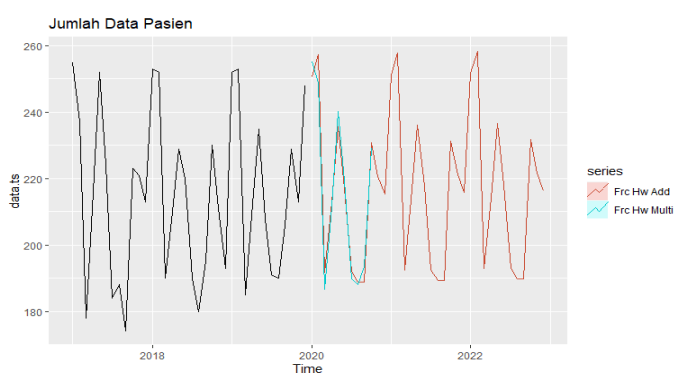

Gbr. 6 Hasil Autoplot Multiplicative

Grafik Pada metode additive didapatkan nilai alpha $=$ 0,00001 , nilai beta $=0,00001$, nilai gamma $=0,00003$. Nilai alpha disini merupakan kestasioneran data, beta merupakan faktor musiman dan gamma merupakan trend data. Kemudian dilakukan pengukuran kesalahan dengan metode additive di dapatkan nilai Mean Square Error (MSE) sebesar 96,3316, nilai Root Mean Square Error (RMSE) sebesar 9,814866, dan nilai Mean Absolut Percentage Error (MAPE) sebesar 3,871016.

Pada metode multiplicative didapatkan nilai alpha $=$ 0,0041 , nilai beta $=0,00001$, nilai gamma $=0,00001$. Kemudian dilakukan pengukuran kesalahan dengan metode multiplicative di dapatkan nilai MSE sebesar 0,001733991, nilai RMSE sebesar 0,04164121, dan nilai MAPE sebesar 3,130697.

MSE merupakan rata-rata kesalahan kuadrat antara nilai aktual dan nilai peramalan, RMSE merupakan metode pengukuran dengan mengukur perbedaan nilai dari prediksi sebuah model sebagai estimasi dari nilai yang diobservasi sedangkan MAPE adalah persentase kesalahan mutlak dari peramalan sehingga didapatkan hasil pengukuran kesalahan metode multiplicative lebih kecil dibandingkan dengan metode additive, sehingga kita dapat menentukan metode multiplicative merupakan metode terbaik untuk melakukan peramalan karena memiliki nilai MAPE yang paling rendah dengan nilai 3,130697.

Metode multiplicative ini dikategorikan sebagai metode dengan peramalan akurasi tinggi karena memiliki nilai MAPE $\leqslant 10 \%$, dengan jumlah MAPE yang mencapai peramalan akurasi tinggi, menandakan nilai prediksi jumlah pasien dari tahun 2020, 2021, dan 2022 dapat digunakan rumah sakit dalam hal pengambilan keputusan untuk melakukan pengembangan fasilitas pelayanan dalam instalasi rawat inap.

\section{Kesimpulan}

Dari hasil pembahasan dapat disimpulkan, metode Triple Exponential Smoothing yang digunakan cocok untuk data 
yang ada. Hasil dari analisis metode multiplicative dikategorikan sebagai metode dengan peramalan akurasi tinggi karena memiliki nilai MAPE $\leqslant 10 \%$, sehingga hasil dari peramalan dapat digunakan rumah sakit dalam hal pengambilan keputusan.

Hasil prediksi jumlah pasien rawat inap untuk 3 tahun kedepan terjadi peningkatan dilihat dari meningkatnya jumlah total pasien setiap tahun, peramalan jumlah pasien tidak berlaku untuk situasi pandemi.

Penelitian ini masi bisa dikembangkan lebih lanjut dengan menggunakan data penyakit terbanyak dirumah sakit, kemudian di analisis musimnya sehingga dapat digunakan untuk pengambilan keputusan rumah sakit. Metode -metode pengambilan keputusan seperti Fuzzy dan Cluster Analysis dapat digunakan untuk kebutuhan ini.

\section{UCAPAN TERIMA KASIH}

Naskah ini merupakan salah satu syarat untuk kelulusan diprogram S2 Magister Sistem Informasi, Fakultas Teknologi Informasi, Universitas Kristen Satya Wacana. Untuk itu saya mengucapkan terimakasih kepada FTI UKSW, RSU GMIM Siloam Sonder dan kepada Tim JOINTER yang telah mendukung sehingga penelitian ini dapat terlaksana dan diterbitkan.

\section{DAFTAR PUSTAKA}

S. Lolita, Nuryadi, dan D. Kusworini, "Analisis Kebutuhan Tempat Tidur Tiap Kelas di Unit Rawat Inap Rumah Sakit Djatiroto Kabupaten Lumajang Analysis of The Needs Each Bed Class In The Inpatient Djatiroto Hospital In Lumajang Regency," 2017.
Produksi dengan Metode Single Eksponensial Smoothing pada Keripik Singkong Srikandi Di Kota Langsa," J. Penelit. Ekon. Akutansi, vol. 2, no. 1, hal. 10-18, 2018.

[3] F. Lawalata dan E. K. O. Sediyono, "Analisis dan Perancangan Sistem Informasi Manajemen Aset Rumah Sakit Berbasis Spatial," JUMANJI, vol. 3, no. 2, hal. 28-33, 2019.

[4] R. Anggrainingsih, G. Aprianto Romadhon, dan S. Sihwi Widya, "Time Series Forecasting Using Exponential Smoothing To Predict The Number of Website Visitor of Sebelas Maret University," Int. Conf. Inf. Technol. Comput. Electr. Eng., hal. 14-19, 2015.

[5] R. Gustriansyah, W. Nadia, dan M. Sofiana, "Komparasi Metode Peramalan Jumlah Permintaan Kamar Hotel," J. Ilm. Inform. Glob., vol. 09, no. 2, hal. 95-100, 2018.

[6] I. Falani, "Penentuan Nilai Parameter Metode Exponential Smoothing Dengan Algoritma Genetik Dalam Meningkatkan Akurasi Forecasting," J. Comput. Eng. Syst. Sci., vol. 3, no. 1, hal. 14-16, 2018.

[7] R. Anggrainingsih, A. Prabanuadhi, dan S. P. Yohanes, "Forecasting The Number of Patients at RSUD Sukoharjo Using Double Exponential Smoothing Holt," 2018 Int. Conf. ICT Rural Dev., hal. 54-58, 2018.

[8] R. P. Kristianto, "Modeling of Time Series Data Prediction using Fruit Fly Optimization Algorithm and Triple Exponential Smoothing," Int. Conf. Inf. Technol. Inf. Syst. Electr. Eng., hal. 407-412, 2019.

[9] G. N. Ayuni dan D. Fitrianah, "Penerapan Metode Regresi Linear Untuk Prediksi Penjualan Properti pada PT XYZ," J. Telemat., vol. 14, no. 2, hal. 79-86, 2019.

[10] W. Setiawan, E. Juniati, dan I. Farida, "The use of Triple Exponential Smoothing Method (Winter) in forecasting passenger of PT Kereta Api Indonesia with optimization alpha, beta, and gamma parameters," Proceeding - 2016 2nd Int. Conf. Sci. Inf. Technol. ICSITech 2016 Inf. Sci. Green Soc. Environ., hal. 198-202, 2017.

[11] P. Gio Ugiana dan D. Irawan Erwin, Belajar Statistika dengan R. 2016. 